\title{
Estrategia educativa en salud bucal para niños y niñas con diversidad
funcional a nivel auditivo
}

Educational strategy in oral health for children and girls with diversity functional at the auditory level

Estratégia Educacional em saúde bucal para crianças e meninas com diversidade funcional no nível auditivo

\author{
Yennifer Rincón Cadavid ${ }^{1}$ \\ Gladys Erlebnis Perea Lemos ${ }^{2}$ \\ Dalma Daneida Garcés Naar ${ }^{3}$ \\ Lina Marcela Correa Incel ${ }^{4}$ \\ Clara Liliana Gallego Gómez ${ }^{5}$
}

Recibido: 28 de septiembre de 2017

Aprobado: 22 de febrero de 2018

Publicado: 20 de marzo de 2019

Cómo citar este artículo: Rincón-Cadavid Y, Perea-Lemos GE, Garcés-Naar DD, CorreaIncel LM, Gallego-Gómez CL. Estrategia educativa en salud bucal para niños y niñas con diversidad funcional a nivel auditivo. Rev Nac Odontol. 2019;15(28):1-11. doi: https://doi.org/10.16925/2357-4607.2019.01.04

Artículo de investigación. https://doi.org/10.16925/2357-4607.2019.01.04

1 Universidad Cooperativa de Colombia https://orcid.org/0000-0002-3816-8648

2 Universidad Cooperativa de Colombia https://orcid.org/0000-0001-5386-0766

3 Universidad Cooperativa de Colombia https://orcid.org/0000-0002-9346-6496 Universidad Cooperativa de Colombia https://orcid.org/0000-0001-5112-3850

5 Universidad Cooperativa de Colombia https://orcid.org/0000-0001-9317-551X 


\section{Resumen}

Introducción: la discapacidad auditiva se refiere a la disminución en la capacidad de oír debido a un problema en el aparato auditivo. Las dificultades para la comunicación entre paciente-odontólogo y la falta de atención odontológica oportuna ocasionan un mayor riesgo para la aparición de las enfermedades bucodentales en esta población.

Objetivo: evaluar el resultado de la implementación de una estrategia educativa en salud oral en niños y niñas con diversidad funcional a nivel auditivo.

Materiales y Métodos: estudio de intervención aplicado en 41 escolares con limitación auditiva entre los 6 y 18 años, la información se obtuvo de encuestas a padres y exámenes clínicos bucales a escolares. Se desarrollaron una serie de estrategias educativas en salud bucal para los participantes y sus cuidadores.

Resultados: el 79,49\% de los padres consideraba que la condición de diversidad funcional influía en la higiene bucal de sus hijos. El $20 \%$ de los padres relatan que en su entidad de salud les negaron la prestación de los servicios a los participantes debido a su condición. Se presentó una diferencia estadísticamente significativa en la disminución de placa bacteriana entre el primer y el segundo examen clínico de los participantes.

Conclusión: una estrategia educativa en salud bucal con enfoque diferencial y que establezca una comunicación adecuada en niños y niñas con necesidades especiales, muestra un resultado positivo en el mejoramiento de la higiene bucal.

Palabras clave: discapacidad auditiva, comunicación, estrategia educativa, salud bucal.

\section{Summary}

Introduction: hearing impairment refers to the decrease in the ability to hear due to a problem in the auditory apparatus. The difficulties for the communication between patient-odontologist and the lack of opportune odontological attention cause a greater risk for the appearance of the oral diseases in this population.

Objective: to evaluate the result of the implementation of an educational strategy in oral health in children with functional diversity at the auditory level.

Materials and Methods: intervention study applied in 41 school children with hearing impairment between 6 and 18 years, information was obtained from surveys of parents and oral clinical examinations of school children. A series of oral health education strategies were developed for the participants and their caregivers.

Results: $79.49 \%$ of the parents considered that the condition of functional diversity influenced the oral hygiene of their children. $20 \%$ of parents report that in their health institution they denied the provision of services to participants due to their condition. There was a statistically significant difference in the decrease of bacterial plaque between the first and the second clinical examination of the participants.

Conclusion: an oral health education strategy with a differential focus and establishing adequate communication in children with special needs shows a positive result in the improvement of oral hygiene.

Key words: auditory disability, communication, educational strategy, oral health. 


\section{Resumo}

Introdução: a deficiência auditiva refere-se à diminuição da capacidade de ouvir devido a um problema no aparelho auditivo. As dificuldades para a comunicação entre o odontologista-paciente e a falta de atenção odontológica oportuna acarretam maior risco para o aparecimento das doenças bucais nessa população.

Objetivo: avaliar o resultado da implementação de uma estratégia educacional em saúde bucal em crianças com diversidade funcional no nível auditivo.

Materiais e Métodos: estudo de intervenção aplicado em 41 escolares com deficiência auditiva entre 6 e 18 anos, as informações foram obtidas a partir de pesquisas com pais e exames clínicos orais de escolares. Uma série de estratégias de educação em saúde bucal foi desenvolvida para os participantes e seus cuidadores.

Resultados: $79,49 \%$ dos pais consideraram que a condição de diversidade funcional influenciou a higiene bucal de seus filhos. $20 \%$ dos pais relatam que em sua instituição de saúde negaram a prestação de serviços aos participantes devido à sua condição. Houve diferença estatisticamente significativa na diminuição da placa bacteriana entre o primeiro e o segundo exame clínico dos participantes.

Conclusão: uma estratégia de educação em saúde bucal com enfoque diferenciado e estabelecendo comunicação adequada em crianças com necessidades especiais mostra um resultado positivo na melhora da higiene bucal.

Palavras-chave: deficiência auditiva, comunicação, estratégia educacional, saúde bucal.

\section{Introducción}

La discapacidad auditiva se refiere a la falta o disminución en la capacidad de oír claramente, debido a un problema en el aparato auditivo (1). Esta puede presentarse en cualquier etapa de la vida y puede variar su grado de severidad según si la causa es genética, congénita o adquirida (2).

Según datos del Instituto Nacional para Sordos del Ministerio de Educación Nacional en Colombia, se encuentran 455.718 con dificultades permanentes para oír, de los cuales 30.285 son menores de 0 a 9 años (3). La Ley 1346 de 2009 de Colombia establece que las personas con discapacidad tienen igualdad de derecho, libertad de expresión y no pueden ser discriminadas por su condición. También deben ser consideradas como personas útiles para la sociedad y se les debe proporcionar un lenguaje para su comodidad que les permita expresarse (4). Para el desarrollo del presente proyecto, y buscando desde el lenguaje la inclusión, se acoge el término diversidad funcional, como aserción al término discapacidad.

En diversos estudios se ha encontrado que las personas con diversidad funcional presentan condiciones precarias de salud bucal, asociadas entre otras, a la mala comunicación con el profesional de la salud y la sensación de estigmatización dada por la sociedad. 
En especial las personas con diversidad funcional a nivel auditivo presentan dificultades en el proceso de atención en los servicios de salud debido a la limitación que presentan para comunicarse, y la poca preparación de los profesionales para la atención diferencial.

La poca empatía entre paciente-odontólogo y la falta de atención en salud genera deterioro de la condición de salud bucal, lo que ocasiona un riesgo muy alto para la aparición de las enfermedades bucodentales (5).

Se ha demostrado que una buena salud bucal favorece en la calidad de vida de las personas con necesidades especiales ya que así se facilitan las necesidades básicas y tendrán una mejor adaptación en la vida social (6).

Por tanto, las campañas en salud bucal buscan implementar estrategias que ayuden a fortalecer y concientizar la importancia de mantener una buena salud bucal. La comunicación para la salud es una estrategia clave destinada a informar a la población sobre aspectos concernientes a la salud, además de otras innovaciones tecnológicas para difundir información sobre salud entre la población, aumenta la conciencia sobre aspectos específicos de la salud individual y colectiva; y sobre la importancia de la salud en el desarrollo (7).

La presente investigación desarrolló una estrategia educativa en salud bucal para menores de edad con diversidad funcional a nivel auditivo.

\section{Materiales y métodos}

La presente investigación se consideró de riesgo mínimo, según la Resolución 8430 de 1993 del Ministerio de Salud de Colombia.

Se realizó un estudio de intervención educativa, con diseño de pre y post en un solo grupo. La población fueron 41 niños de una institución educativa de la ciudad, que atiene la población en edad escolar con diversidad funcional a nivel auditivo. Después de obtener la autorización de las directivas de la institución, se realizó una reunión informativa para padres de familia explicando el objetivo de la investigación, y se firmaron los consentimientos informados con los padres o acudientes de los participantes y el asentimiento del menor para participar en la investigación.

El proyecto se desarrolló en tres fases. En la primera fase se realizó una encuesta estructurada sobre conocimientos de salud oral a los padres de familia en la cual se incluyeron las variables sociodemográficas, acceso a los servicio de salud bucal, conocimientos de salud bucal, hábitos de higiene oral y presencia de dieta cariogénica. La encuesta fue validada a través de una prueba piloto previa. Posteriormente, se realizó la evaluación cuantitativa de la higiene bucal con el índice de placa bacteriana 
de Silness y Löe, y el examen de caries dental según los criterios ICDAS a los participantes. Para llevar a cabo el examen clínico bucal se realizó un proceso de estandarización de los examinadores.

En la segunda fase se realizó la implementación de la estrategia educativa, para ello se contó con la asesoría de una licenciada en pedagogía infantil. Se diseñó un plan de aula para intervención. Como primer momento de interacción se realizó una actividad de acercamiento a los niños, a partir de una pinta carita con los niños más pequeños, y con los mayores se realizó el juego de sopa de letras.

La segunda semana se realizó una actividad de reconocimiento sobre lo que afectaba o favorecía la salud bucal, a partir de imágenes relacionadas con salud bucal para que las colorearan. Terminada la actividad se continuó con otra actividad lúdica (rompe cabezas gigante), con el objetivo de descubrir una imagen relacionada con la salud bucal y reconocer en ella cada uno de los personajes que aparecían.

En la tercera semana se llevó a cabo una presentación con títeres que relata una historia sobre la importancia de mantener una buena higiene bucal y la realización de un juego lúdico con una ruleta en la cual se colocaron varias actividades, y los participantes debían girarla y realizar la actividad que la flecha señalara. Como última actividad se desarrolló el juego de par en par en donde se colocaron 15 pares de imágenes al revés de tal forma que los participantes no las pudieran ver y poder ir formando los pares a medida que se iban descubriendo y se mostró un video educativo acerca de la forma correcta de realizar la higiene oral. Se entregaron kits de cepillado para incentivar buenos hábitos bucales.

En la tercera fase se realizó nuevamente la encuesta de conocimientos a los padres de familia y a los participantes, y se aplicó un segundo examen bucal para determinar el índice de placa bacteriana.

Para el análisis estadístico se realizó un análisis descriptivo de las variables sociodemográficas, el índice cop y el índice de placa. Se compararon las medidas del índice de placa de la primera revisión con las medidas en la segunda revisión, con la realización de Paired T-test. Se usó un nivel de significancia del 0,05\%. El análisis se realizó en el programa SPSS versión 18.

\section{Resultados}

Durante el seguimiento quedaron excluidos diez participantes por falta de continuidad en las actividades de la segunda fase. Por tanto, se realizaron los análisis con una muestra de 31 participantes. Los participantes tenían entre 6 y 18 años; el 47,2 \% eran niñas y el 52,7 \% niños. El 52,5 \% se encontraban afiliados al régimen contributivo, el 
$42,5 \%$ al régimen subsidiado, el 2,5\% a medicina prepagada y el 2,5\% restante se encuentra en otras entidades especiales como Ecopetrol, Fuerzas Armadas y Magisterio

Aunque el 79,49 \% de los padres de familia manifestaron que la condición de diversidad funcional a nivel auditivo influía en la higiene bucal de sus hijos (figura 1). Sólo el 65 \% de éstos realiza un acompañamiento a las prácticas de cuidado en higiene oral de sus hijos/as.

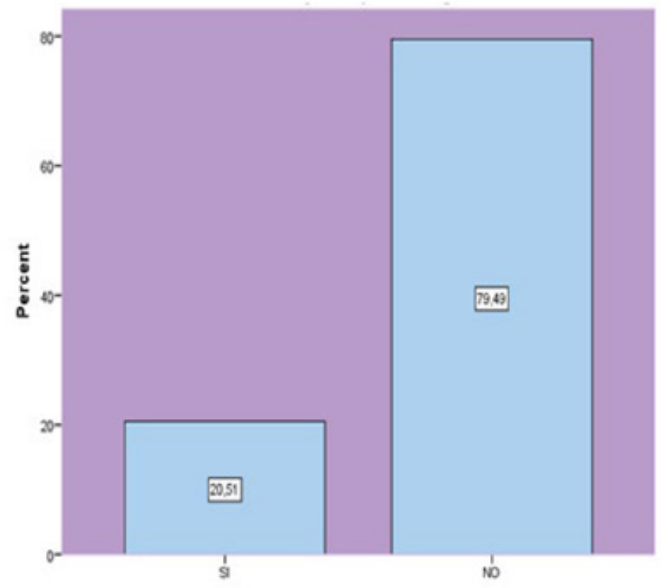

Figura 1. Influencia de la discapacidad auditiva sobre una adecuada higiene bucal. Fuente: elaboración propia

De acuerdo con las prácticas de higiene bucal se encontró que sólo el 49 \% de los niños cepillan sus dientes tres veces al día (figura 2).

\section{- Una vez Dos veces}

\section{- Tres veces $\quad$ Ninguna}

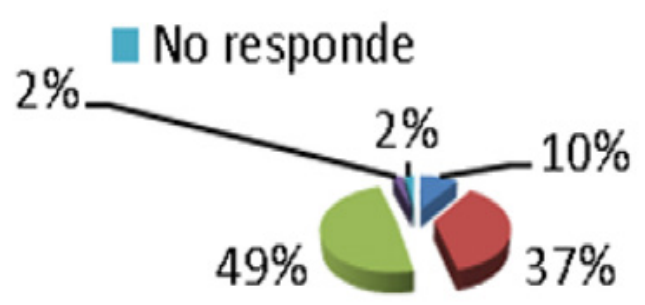

Figura 2. Frecuencia del cepillado dental.

Fuente: elaboración propia 
El $52 \%$ de los padres de familia afirmaron llevar a sus hijos al odontólogo al menos una vez al año. El 20 \% de los padres relataron que su entidad de salud negó la prestación del servicio a sus hijos por su condición de diversidad funcional.

Los padres refirieron en un 57,14 \%, los padres refirieron que la relación de su hijo con el odontólogo era buena al momento de la consulta, pero el 31,43\% reportó que esta era regular y el 11,43 \% reportó que la relación del profesional con su hijo era mala (figura 3).

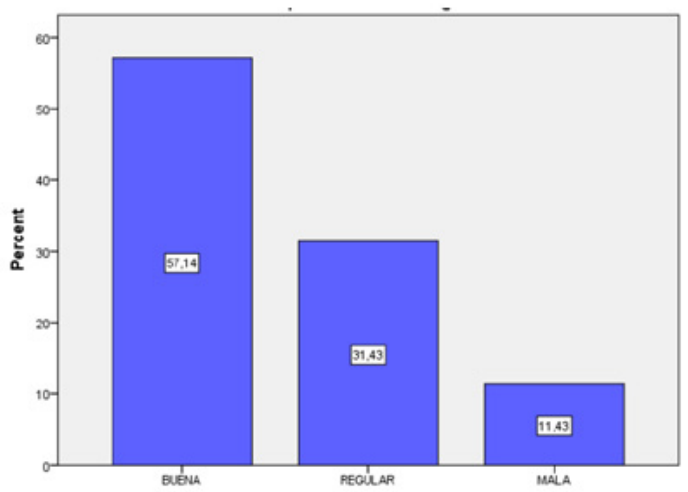

Figura 3. Relación entre el profesional y el paciente durante la cita odontológica. Fuente: elaboración propia

Para el análisis de la caries dental se agruparon en tres rangos, caries incipientes que agrupa los códigos 1 y 2, caries moderada con códigos 3 y 4, y caries severa para los códigos 5 y 6 . Se presentan los códigos en dientes permanentes. Para un total de caries incipientes de 4,4, caries moderada 0,86 y caries severa de 0,80. Según la experiencia de caries, se tiene un $20 \%$ de la población con caries severa, y un $77 \%$ con caries incipientes. El valor promedio del cop en dientes permanentes fue de 1,1.

Se observa en la comparación entre la primera recolección del porcentaje de placa bacteriana y la segunda toma, que la media en el examen inicial fue de 48,8 \% con una desviación típica de 23,3 \%; y en el segundo examen la media fue de 31,9\% con una desviación típica de 18,07\%.

En el primer examen el valor mínimo de placa bacteriana fue de $6 \%$, mientras que el valor máximo fue de $100 \%$; en el segundo examen se notó que el valor mínimo de placa encontrado fue de $0 \%$ y el valor máximo de $60 \%$, se presentó una diferencia estadísticamente significativa en la disminución de placa bacteriana del segundo examen (figura 4). 
Boxplot para el índice de placa antes y después

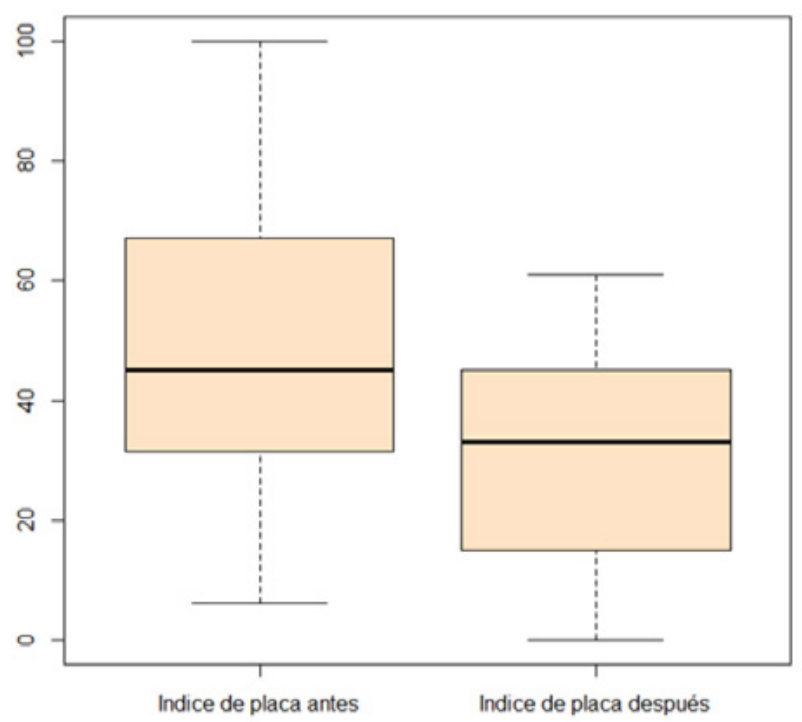

Figura 4. Comparación entre examen de placa bacteriana inicial y examen final de los niños y niñas con diversidad funcional.

Fuente: elaboración propia

\section{Discusión}

La utilización de una estrategia educativa en salud bucal es una herramienta útil en la enseñanza de los conceptos básicos sobre salud bucal, siempre que se mantenga la motivación de los participantes y se utilicen estrategias didácticas, lúdicas y acordes a las necesidades de los participantes (8-10).

Se encontró con el índice cop para los niños con diversidad funcional a nivel auditivo de 6-18 años es de 1,1, resultados más bajos que lo reportado en el ENSAB IV, con un cop de 1,51 a los 12 años 2,3 a los 15 años y 3,1 a los 18 años (11), lo que puede ser explicable por la edad de los participantes próximos a los seis años, con dientes recién erupcionados.

A pesar que de que el acompañamiento de los padres de familia es fundamental a la hora de realizar la higiene bucal; en la presente investigación se encontró que este acompañamiento es un poco más de la mitad de los niños (porcentaje del 65 \%); este resultado es comparable con lo reportado por Kenney (12), quien afirma que los padres de niños con necesidades especiales enseñaban menos a sus hijos a tener una buena salud bucal, así pues, presentaban más problemas dentales comparado con los niños sin necesidades especiales. 
La Asociación Dental Americana (ADA), y otras organizaciones, han informado sobre las limitaciones de acceso a las personas con discapacidad, resultados comparables con los de la presente investigación, donde el 20 \% de los participantes relatan cómo en el último año ninguna entidad les prestó servicios de salud debido a la condición de discapacidad que presentan sus hijos. Resultados comparables a lo encontrado por Davies, quien reporta cómo las personas con necesidades especiales reciben menos atención en salud oral, o una atención de menor calidad, que la población general (13).

Loreda (14) encontró como que la implementación de estrategias educativas en personas con discapacidad auditiva es adecuada para mejorar las prácticas de higiene bucal en éstos, resultados comparables con el presente estudio.

Castillo (10) utilizó una versión modificada de uno de los juegos tradicionales en la cultura popular de México, el juego "serpientes y escaleras" que logró incrementar de manera significativa los conocimientos sobre conceptos básicos de salud en los participantes. También Díaz (15) a través de la realización de una estrategia educativa lúdica en niños escolares, reporta cómo el nivel de motivación de los niños aumentó. Estos resultados comparables con los obtenidos en la presente investigación, muestran la importancia de mantener la motivación en los participantes y la necesidad de integrar actividades lúdicas y participativas para la enseñanza de la higiene oral.

\section{Conclusiones}

Una estrategia educativa en salud bucal que establezca una comunicación adecuada en niños y niñas con necesidades especiales, muestra un resultado positivo en la mejoría de la higiene bucal.

Los niños y niñas con diversidad funcional a nivel auditivo requieren un tratamiento específico y de calidad, un acompañamiento continuo de los padres para mantener así una higiene bucal adecuada.

Es de suma importancia que el profesional de la salud esté capacitado para atender a personas con limitaciones para que permita brindarles atención con enfoque diferencial, basadas en una correcta comunicación entre el profesional y el paciente. 


\section{Referencias}

1. Organización Mundial de la Salud, Banco Mundial. Discapacidades. [Internet]. [Consultado 1 de noviembre de 2018]. Recuperado en: http://www.who.int/topics/disabilities/es/

2. Caballería B, Vergara A. Hacia una comprensión de los significados otorgados por sujetos/ as Sordos/as de la Corporación de Sordos de Valparaíso, a su relación con oyentes en el ámbito del empleo. Valparaíso. Trabajo de grado (Trabajador Social y Grado de Licenciado en Trabajo Social). Valparaíso: Pontificia Universidad Católica de Valparaíso: Facultad de Ciencias Económicas y Administrativas; 2012.

3. Ministerio de Educación Nacional. Instituto Nacional de Sordos. Estadísticas Básicas de población sorda Colombia. [Internet]. [Consultado el 1 de abril de 2018]. Recuperado en: http:// www.insor.gov.co/observatorio/estadisticas-basicas-poblacion-sorda-colombiana

4. Colombia. Congreso de la República. Ley 1346 de 2009. Por medio de la cual se aprueba la "Convención sobre los Derechos de las personas con Discapacidad", adoptada por la Asamblea General de la Naciones Unidas el 13 de diciembre de 2006. Bogotá: El Congreso; 2009.

5. Donato J, Batista A, Soares R, Tavares M, Magalhaes M. Identity of the deaf and interventions in health from the perspective of a community of sign language users. 2011. Ciênc. Saúde Coletiva. 2012; 17(3): 1-9. doi: http://dx.doi.org/10.1590/S1413-81232012000300013

6. Lozano L. Odontología y discapacidad. [Internet]. [Consultado el 1 de noviembre de 2018]. Recuperado en: http://www.fundacionprevent.com/app/webroot/news/Infounomas/PDFS/ odontologia_discapacidad.pdf

7. OMS (AMPRO/PAHO). Un marco y Guía de Actuación. Washington: OMS; 1996.

8. Limonta ER, Araujo T. Intervención educativa para modificar conocimientos sobre salud bucal en escolares de tercer grado. Santiago de Cuba. Clínica estomatológica provincial docente. MEDISAN 2000; 4(3): 9-15.

9. Martin C. Intervención educativa en salud bucal dirigida a educandos de la Escuela Bolivariana Primaria: “Pedro María Ureña”. Tesis. Venezuela. 2005. [Internet]. [Consultado el 12 de septiembre de 2017]. Recuperado en: http://www.ilustrados.com/tema/10591/ Intervencion-educativa-salud-bucal-dirigida-educandos.html

10. Castillo JM, Rodríguez M, Guerrero F. El juego como alternativa para la enseñanza de conceptos básicos de salud. México, Durango. Rev Panam Salud Publica. 2001; 9(5): 311-4 
11. Colombia, Ministerio de Salud y Protección Social. IV Estudio Nacional de Salud Bucal. Situación en Salud Bucal. 2014. Recuperado de: https://www.minsalud.gov.co/sites/rid/ Lists/BibliotecaDigital/RIDE/NS/PP/ENSAB-IV-Situacion-Bucal-Actual.pdf

12. Kenney M, Kogan M, Crall J. Parental Perceptions of Dental/Oral Health Among Children With and Without Special Health Care Needs. Academic Pediatrics. 2008; 8(5): 312-20:1-9. doi: https://doi.org/10.1016/j.ambp.2008.04.005

13. Davies R, Bedi R, Scully C. Oral health care for patients with special needs. BMJ. 2000; 321: 497. doi: https://doi.org/10.1136/bmj.321.7259.495

14. Loreda M, Maty SR. Intervenciones de comunicación exitosas para el cuidado a la salud en personas con deficiencia auditiva. Enferm Univ. 2012; 9(4): 57-69.

15. Castillo JM, Rodríguez M, Guerrero F. El juego como alternativa para la enseñanza de conceptos básicos de salud. México, Durango. Rev Panam Salud Publica. 2001; 9(5): 311-4. 